\title{
Magnetic resonance imaging-guided vacuum-assisted breast biopsy: experience and preliminary results of 205 procedures
}

\author{
Biópsia a vácuo guiada por ressonância magnética: experiência e resultados preliminares de 205
} procedimentos

\section{Gracy de Almeida Coutinho Carneiro ${ }^{1, a}$, Fernanda Philadelpho Arantes Pereira ${ }^{1, b}$, Flávia Paiva Proença Lobo Lopes $^{1, c}$, Maria Julia Gregorio Calas ${ }^{1, d}$}

1. Clínica de Diagnóstico Por Imagem (CDPI), Rio de Janeiro, RJ, Brazil.

Correspondence: Dra. Gracy de Almeida Coutinho Carneiro. Rua Senador Vergueiro, 232/1103, Flamengo. Rio de Janeiro, RJ, Brazil, $22230-001$. Email: gracyacoutinho@gmail.com.

a. https://orcid.org/0000-0002-3884-7667; b. https://orcid.org/0000-0003-4855-8065; c. https://orcid.org/0000-0002-6713-4041; d. https://orcid.org/0000-0002-7029-8530.

Received 8 August 2017. Accepted after revision 7 December 2017.

How to cite this article:

Carneiro GAC, Arantes Pereira FP, Lopes FPPL, Calas MJG. Magnetic resonance imaging-guided vacuum-assisted breast biopsy: experience and preliminary results of 205 procedures. Radiol Bras. 2018 Nov/Dez;51(6):351-357.

Abstract Objective: To demonstrate the frequency of malignancy and histological characteristics of lesions in patients submitted to vacuumassisted breast biopsy guided by magnetic resonance imaging (MRI).

Materials and Methods: This was a retrospective study of MRI-guided vacuum-assisted breast biopsies performed between April 2008 and December 2016, in which we analyzed clinical and epidemiological data, as well as the BI-RADS classification and histopathological results. We compared nodules and non-nodular enhancements, in terms of their correlation with malignancy, using chi-square test.

Results: Among 215 cases referred for MRI-guided vacuum-assisted breast biopsy, the procedure was contraindicated in 10 cases (5\%) and was technically feasible in the remaining 205 (95\%). Non-nodular enhancements were observed in 135 cases (66\%), and nodules were observed in 70 (34\%), with a mean diameter of $2.2 \mathrm{~cm}$ (range, $0.5-9.6 \mathrm{~cm}$ ) and $0.97 \mathrm{~cm}$ (range, $0.5-2.2 \mathrm{~cm})$, respectively. Of the 205 lesions analyzed, 43 (21\%) were malignant, 129 (63\%) were benign, and 33 (16\%) were classified as high-risk lesions. The most common histological findings were invasive ductal carcinoma and, in high-risk cases, lobular neoplasia. There was no significant difference between nodules and non-nodular enhancements in terms of the rate of malignancy $(p=0.725)$.

Conclusion: In our sample, the overall malignancy rate was $21 \%$. However, to improve the assessment of these results, it is necessary to correlate them with the surgical data and with data from the follow-up of benign cases.

Keywords: Image-guided biopsy/methods; Breast; Magnetic resonance imaging; Breast neoplasms/diagnosis.

Resumo Objetivo: Demonstrar a frequência de malignidade e as características histológicas das lesões encontradas em pacientes submetidas a biópsia a vácuo guiada por ressonância magnética (RM).

Materiais e Métodos: Estudo retrospectivo, realizado no período de abril de 2008 a dezembro de 2016, de biópsia a vácuo guiada por RM, em que se analisaram dados clinicoepidemiológicos, classificação BI-RADS e resultados histopatológicos. A comparação entre os nódulos e os realces não nodulares e a presença de malignidade foi realizada utilizando-se o teste de qui-quadrado.

Resultados: Dos 215 casos com indicação de biópsia a vácuo guiada por RM, 10 (5\%) foram contraindicados e os restantes 205 (95\%) foram tecnicamente viáveis. Foi observado que 66\% eram realces não nodulares (135 lesões) e $34 \%$ eram nódulos (70 lesões), medindo, em média, 2,2 cm (0,5-9,6 cm) e 0,97 cm (0,5-2,2 cm), respectivamente. Das 205 lesões analisadas, 43 (21\%) eram malignas, 129 (63\%) eram benignas e 33 (16\%) eram de alto risco. 0 achado histológico mais frequente nos casos de malignidade foi o carcinoma ductal infiltrante, e nos casos de alto risco, as neoplasias lobulares. Não houve diferenças estatisticamente significantes entre os nódulos e realces não nodulares em relação a malignidade $(p=0,725)$.

Conclusão: Na nossa amostra, a taxa global de malignidade foi de $21 \%$. No entanto, é necessário correlação com dados cirúrgicos e seguimento nos casos benignos, para melhor avaliação dos resultados.

Unitermos: Biópsia guiada por imagem/métodos; Mama; Ressonância magnética; Neoplasias da mama/diagnóstico.

\section{INTRODUCTION}

Magnetic resonance imaging $(\mathrm{MRI})$ of the breast is an imaging technique that is increasingly used in clinical practice, with an established role in the diagnosis, staging, and follow-up of breast cancer ${ }^{(1-3)}$. Among cancer patients,
MRI detects additional cancer foci in the ipsilateral breast in $6-34 \%$ and in the contralateral breast in $4-24 \%{ }^{(4)}$. In addition, MRI is able to detect lesions that are not visible on physical examination, mammography, or ultrasound ${ }^{(4,5)}$. According to Liberman et al. ${ }^{(4)}$, MRI detects $2-8 \%$ of 
breast neoplasms in high-risk patients in whom mammography and physical examination are normal.

MRI of the breast presents high (90-94\%) sensitivity and variable $(37-72 \%)$ specificity, making it necessary to confirm the malignancy of a suspicious lesion ${ }^{(4,6,7)}$. When the lesion has not been identified by other methods, MRI is used, either for preoperative marking followed by surgical excision or for percutaneous biopsy ${ }^{(8,9)}$.

Vacuum-assisted biopsy is a safe and effective technique for the management of lesions detectable only on MRI and has excellent accuracy, even for small lesions $^{(10-12)}$. In addition, because it is a minimally invasive method, it is an alternative to surgical biopsy, without the complications and high costs associated with surgery, especially in cases of benign lesions ${ }^{(5,13)}$. It also enables the placement of a titanium clip (which can then be seen with other imaging methods), with the purpose of marking the affected region, in order to facilitate the follow-up or subsequent procedures $^{(5)}$.

Although the results of MRI-guided vacuum-assisted biopsy are well established in the international literature and consensuses, data related to the results of such procedures in Brazil are still scarce. Therefore, the objective of this study was to evaluate the histopathological results and the malignancy rate found in the lesions subjected to MRIguided biopsy at our center.

\section{MATERIALS AND METHODS}

We conducted a retrospective study of 190 women, in whom a total of 215 MRI-guided biopsies were requested at a private clinic. Among those, biopsies were obtained from 205 lesions that could be seen only on MRI.

We used a database of patients submitted to MRIguided vacuum-assisted biopsy at our center between April 2008 and December 2016. Clinical, epidemiological, histopathological, and breast MRI data were analyzed. All MRI scans were classified according to the Breast Imaging Reporting and Data System (BI-RADS) criteria $^{(14)}$ as BIRADS 5, 4, or 3, the last being assigned to patients with high familial/genetic risk or with a current diagnosis of breast cancer. Patients were advised about the procedure, post-intervention follow-up, and possible complications. All participating patients gave written informed consent.

For information management purposes, a new database containing the patient data was created with Microsoft Excel 2000, following the method used in the research protocols. After the study had been approved by the local research ethics committee, data were collected and entered into a specific electronic form.

The MRI-guided vacuum-assisted biopsies were performed by two radiologists specializing in diagnostic and interventional breast imaging. A 1.5 T MRI scanner (Signa Excite HD; GE Healthcare, Milwaukee, WI, USA) was used for the procedures. Patients were placed in the prone position, and the images were acquired with a dedicated

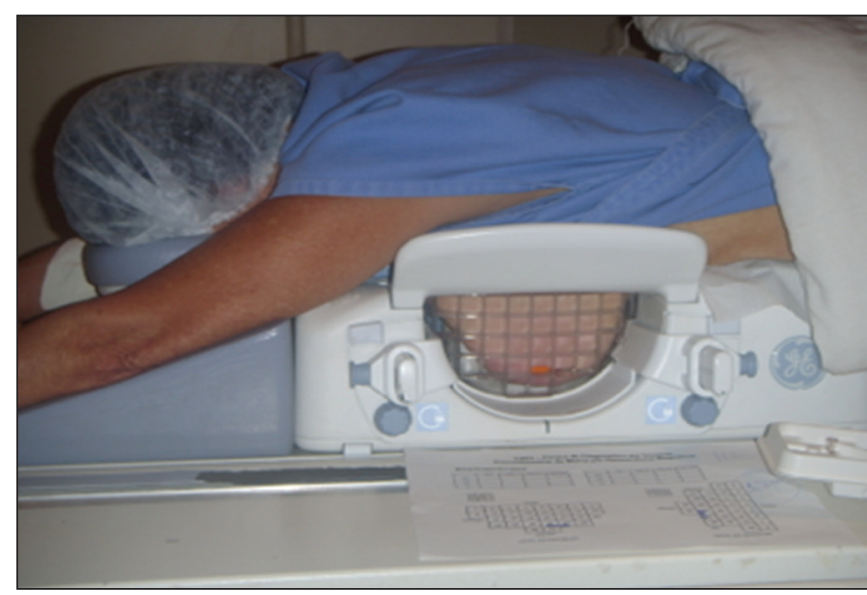

Figure 1. Patient positioned for the procedure, with the vitamin capsule, biopsy grid, and schematic diagram used in order to guide the biopsy.

8-channel coil, which provides lateral and medial access to the breast (Figure 1). The target breast was compressed and immobilized. A vitamin capsule, used as marker, was placed on the skin over the region where the lesion was supposedly located, based on a review of the previous MRI study, and a schematic diagram with its location was created to be used as a guide during the procedure (Figure 2).

First, a localization sequence was acquired and the volume of interest was selected so as to include the entire compression system and the vitamin capsule. Next, sagittal fat-suppressed three-dimensional T1-weighted gradient sequences (flip angle, $15^{\circ}$; bandwidth, 41.67 MHz; matrix, $220 \times 220$; FOV, $220 \mathrm{~mm}$; NEX, 1; slice thickness, $2 \mathrm{~mm}$; and interslice gap, $0 \mathrm{~mm}$ ) were acquired before and after injection via a rapid infusion pump of $0.1 \mathrm{mmol} / \mathrm{L}$ gadoterate meglumine (Dotarem; Guerbet, Roissy, France) per kilogram of body weight, followed by $20 \mathrm{~mL}$ of saline solution, until enhancement of the target lesion was observed.

On the monitor, the cursor was placed over the lesion. The relationship between the lesion and the surface of the skin, as well as that between the lesion and the vitamin capsule, was determined by observing sequential sagittal images. The compression grid appeared as lines with hypointense signals on the skin surface, secondary to the pressure of the grid on the skin. The vitamin capsule appeared as an oval shape, with a hyperintense signal, near the skin surface. The needle entry site was determined based on the analysis of the relationship of the lesion to the grid lines, using the vitamin capsule and the positioned cursor as guides; the skin entry site was registered in the schematic diagram (Figure 2). The depth of the lesion was calculated on the basis of the difference between the position of the slice that showed the skin surface and that of the slice that contained the lesion.

After asepsis with $70 \%$ alcohol, we anesthetized the skin surface with $5 \mathrm{~mL}$ of $1 \%$ lidocaine hydrochloride, without vasoconstrictors, prioritizing the needle path. We used a biopsy kit (Suros ATEC; Hologic, Marlborough, MA, USA) containing a needle guide, coaxial cannula 


\section{MRI procedures of the breast}

\section{Right lateral breast}

\begin{tabular}{|c|l|l|l|l|}
\hline & Vitamin E & Lesion A & Difference & Needle/clip \\
\hline LR & & & & \\
\hline AP & & & & \\
\hline SI & & & & \\
\hline
\end{tabular}

\begin{tabular}{|c|c|c|c|c|}
\hline & Vitamin E & Lesion B & Difference & Needle/clip \\
\hline LR & & & & \\
\hline AP & & & & \\
\hline SI & & & & \\
\hline
\end{tabular}

LR, left-right

AP, anterior-posterior

SI, superior-inferior
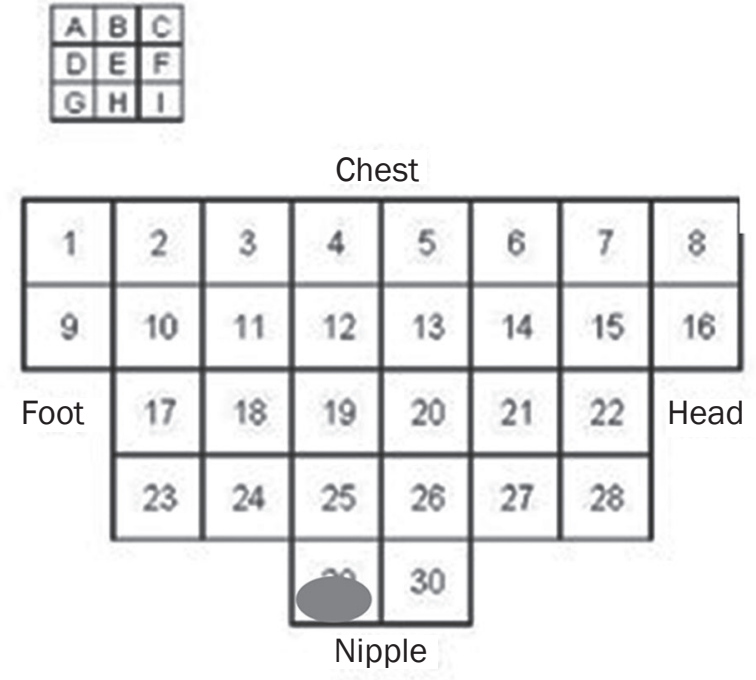

PATIENT VIEW
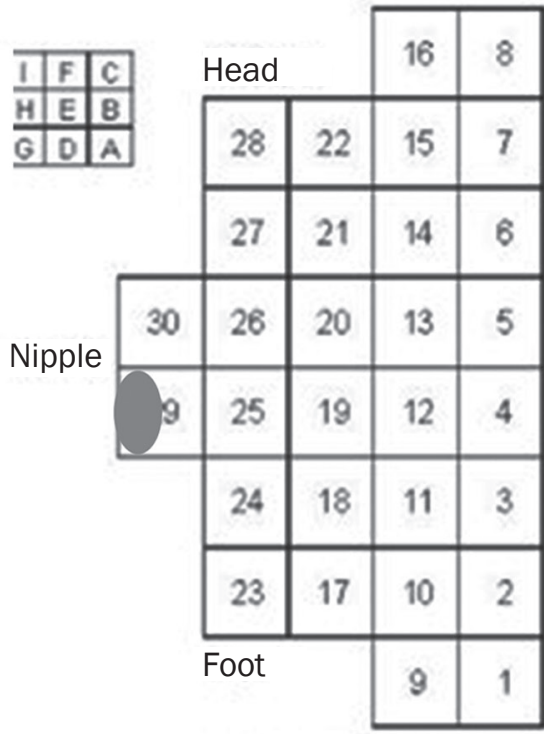

MONITOR VIEW

Figure 2. Schematic diagram used in order to guide the biopsy: in this case, lateral access to the right breast will be used.

(made of sterile plastic), stylet (made of titanium), and obturator. The needle guide was placed on the grid. The coaxial cannula, together with the stylet, was inserted until it reached the calculated depth. The stylet was then removed and replaced with the obturator, which is visible on MRI.

Another sagittal fat-suppressed T1-weighted sequence, with or without axial reconstruction, was then acquired to document the location of the obturator. The obturator appeared as a structure with a hypointense signal, often accompanied by an adjacent magnetic susceptibility artifact, which hindered the identification of smaller target lesions. In such cases, adjacent anatomical landmarks were useful in confirming the location of the lesion in relation to the obturator (Figure 3).

Once the obturator was correctly positioned in relation to the lesion, the patient was removed from the scanner and tissue samples were collected with the ATEC 9-gauge vacuum-assisted breast biopsy device (Hologic) through the coaxial cannula. After the samples had been collected, a titanium marker was inserted and another sagittal fat-suppressed T1-weighted sequence was acquired in order to verify the relationship between the titanium marker and the biopsied region. After the biopsy, manual compression was applied in order to ensure hemostasis. Subsequently, a sterile pressure dressing was placed over the wound and unilateral two-view mammography (in craniocaudal and lateral views) was performed to confirm the successful placement of the clip. The duration of the procedure was defined as the time from the acquisition of the localization MRI sequence to the last MRI sequence acquired, after the placement of the titanium marker. The specimens were analyzed by pathologists with experience in breast pathology.

The report containing the MRI images was given to the patients, along with their histopathological results, 15 days after the procedure. The report also included the correlation, established by the radiologist, between the biopsied image and its histopathology.

A comparative, exploratory statistical analysis was conducted using the SPSS Statistics software package, version 20.0 (IBM Corp., Armonk, NY, USA). Categorical variables are presented as absolute and relative frequencies, whereas continuous variables are presented as means and standard deviations. To distinguish nodules from non-nodular enhancements and to identify malignancy, we used Pearson's chi-square test with a significance level of $5 \%(p=0.05)$. 


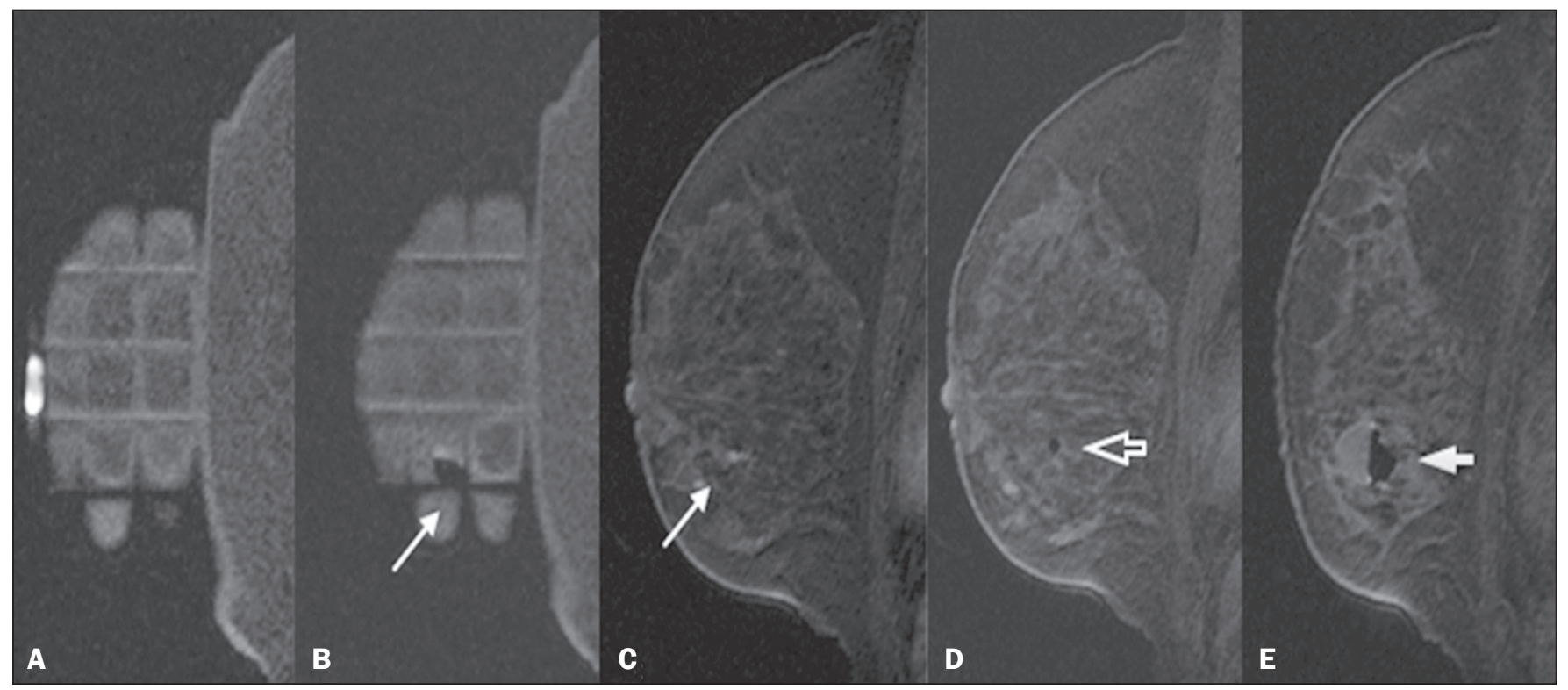

Figure 3. Sagittal fat-suppressed T1-weighted MRI scan of a 53-year-old woman submitted to vacuum-assisted biopsy (approach: left breast, lateral). A: Image of the vitamin capsule and the grid. B: Image of the grid and needle positioned for the procedure (arrow). C: Image of the lesion (arrow). D: Image of the obturator in the lesion (arrow). E: Post-biopsy scan showing a hematoma (arrow).

\section{RESULTS}

Among a total of 215 cases referred for MRI-guided vacuum-assisted biopsy, the procedure was contraindicated in ten: because the lesion could not be identified at the time of the procedure, in six cases; because the lesion was in close proximity to the breast implant, in two; because the lesion was in close proximity to the nipple, in one; and because the lesion was located posterior to the biopsy grid, in one. Therefore, MRI-guided vacuum-assisted biopsy was performed for 205 lesions in 190 women between 26 and 85 years of age (mean age, 52 years). The proportion of technically feasible biopsies was $95 \%$.

The most common complication of the procedure was hematoma $(n=6 ; 2.93 \%)$. Other complications included skin lesion $(\mathrm{n}=1 ; 0.49 \%)$ and vasovagal reaction $(\mathrm{n}=2$; $0.98 \%$ ). All of the complications were considered mild and self-limiting, not requiring intervention or hospitalization.

Of the 205 lesions biopsied, $135(66 \%)$ were nonnodular enhancements and $70(34 \%)$ were nodules. The non-nodular enhancements measured between $0.5 \mathrm{~cm}$ and $9.6 \mathrm{~cm}$ (mean, $2.2 \mathrm{~cm}$ ), whereas the nodules measured between $0.5 \mathrm{~cm}$ and $2.2 \mathrm{~cm}$ (mean, $0.97 \mathrm{~cm}$ ). Of the 205 lesions, $129(63 \%)$ were benign, $43(21 \%)$ were malignant, and 33 (16\%) were high-risk lesions (encompassing nodules and non-nodular enhancements). There was no statistically significant difference between nodules and non-nodular enhancements in terms of malignancy $(p=0.725)$.

The BI-RADS lexicon was used for the findings of the pre-biopsy MRI scans. Of the 205 lesions evaluated, seven (four malignant lesions and three benign lesions) were classified as BI-RADS 5; 190 (39 malignant lesions, 119 benign lesions, and 32 high-risk lesions) were classified as
BI-RADS 4; and eight (seven benign lesions and one highrisk lesion) were classified as BI-RADS 3.

The mean duration of the MRI-guided vacuum-assisted biopsy procedures performed in the present study was 26 min (range, 15-61 min), the duration varying depending on the number of target lesions and degree of difficulty of the procedure. During each procedure, we obtained no fewer than seven and no more than 20 fragments. The number of fragments obtained varied according to breast size; number, location, and size of the lesions; difficulty in performing the technique; and the presence of complications, such as bleeding and a vasovagal response.

A breakdown of the histological types of the 205 lesions can be seen in Table 1. The most common benign results were fibrocystic changes, followed by fibroadenomas, whereas the most common malignant results were ductal carcinomas, including the invasive and in situ forms. Among the high-risk lesions, the most common finding was lobular neoplasia.

\section{DISCUSSION}

MRI-guided vacuum-assisted biopsy is a relatively new procedure when compared with stereotactically- and ultrasound-guided biopsies. It is indicated for lesions identified only on MRI (nodules and non-nodular enhancements); that is, lesions that are not visible on other imaging methods, such as mammography, tomosynthesis and ultrasound $^{(1,5,8,15,16)}$.

As described in the literature, the cancer detection rate of MRI-guided vacuum-assisted biopsy ranges from $17 \%$ to $61 \%$; most studies report rates between $20 \%$ and $40 \%$, comparable to those obtained in other types of imaging-guided biopsies ${ }^{(4,11-13,17-26)}$. The rate of technically 
Table 1-Histopathological results of the biopsies.

\begin{tabular}{|c|c|}
\hline Histopathological result & $\begin{array}{l}\text { Number } \\
\text { of lesions }\end{array}$ \\
\hline \multicolumn{2}{|l|}{ Malignant lesions } \\
\hline Infiltrating ductal carcinoma & 18 \\
\hline Ductal carcinoma in situ & 17 \\
\hline Infiltrating lobular carcinoma & 5 \\
\hline Undetermined carcinoma & 2 \\
\hline Invasive papillary carcinoma & 1 \\
\hline \multicolumn{2}{|l|}{ High-risk lesions } \\
\hline Lobular neoplasia & 11 \\
\hline Papilloma & 8 \\
\hline Atypical ductal hyperplasia & 6 \\
\hline Columnar cells changes with atypia & 4 \\
\hline Radial scar & 3 \\
\hline Atypical ductal hyperplasia + atypical lobular hyperplasia & 1 \\
\hline \multicolumn{2}{|l|}{ Benign lesions } \\
\hline Fibrocystic changes & 77 \\
\hline Secretory lobular changes & 19 \\
\hline Fibroadenoma & 13 \\
\hline Sclerosing adenosis & 9 \\
\hline Post-radiation changes & 7 \\
\hline Steatonecrosis & 2 \\
\hline Lipoma & 2 \\
\hline Total & 205 \\
\hline
\end{tabular}

feasible biopsies in our study was considered satisfactory $(95 \%)$ and is in agreement with the $93-100 \%$ reported in other studies $^{(4,11-13,17-26)}$.

In the present study, the MRI-guided vacuum-assisted biopsy was canceled in ten cases. The most common contraindication was lesion nonvisualization at the time of the biopsy, which occurred in six $(2.8 \%)$ of the 215 cases. Other contraindications were lesion proximity to a breast implant (two cases) and to the nipple (one case), as well as the lesion being positioned posteriorly to the biopsy grid (one case). In the literature, a cancelation rate of $2-16 \%$ is reported for this type of procedure ${ }^{(25,27)}$. Lesion nonvisualization usually occurs due to differences in positioning that cause changes in the location of the lesion, compression of the breast leading to reduced blood flow to the lesion, or the procedure being performed during the incorrect phase of the menstrual cycle. These effects can be minimized by scheduling the procedure in the second or third week of the menstrual cycle, decreasing compression, and, in some cases, using delayed image acquisition ${ }^{(4,5,8,27)}$. In our study, the attending physician was the one who decided how to manage the ten cases in which the procedure was contraindicated. However, when in accordance with the criteria established for the BI-RADS category, surgical biopsy was recommended if the lesion could not be biopsied, whereas short-term MRI follow-up was recommended for the cases of lesion nonvisualization on the day of the procedure, as described in the literature ${ }^{(27,28)}$.

Because the present study was conducted at a private clinic that accepts health insurance plans, patient adherence to follow-up was not always optimal: some patients do not bring their surgery reports back to us or do not return for a follow-up examination. It is therefore difficult to define the underestimation rate of the lesions submitted to MRI-guided vacuum-assisted biopsy and the accuracy of the method. The next step of our study will be to seek follow-up data and surgical biopsy results of the patients who underwent surgery.

We compared the results of our 205 cases with those of the samples evaluated in 14 articles published between 2001 and $2016^{(4,11-13,17-26)}$, with lesion sample sizes ranging from 29 to 538 (Table 2).

The mean duration of the MRI-guided vacuum-assisted biopsy $(26 \mathrm{~min})$ and the number of fragments removed during the procedure $(n=7-20)$, as well as the fact that there were no serious complications, were similar to the findings of the other 14 studies evaluated, especially those that used the same device and probe size

Table 2-Comparison with published MRI-guided vacuum-assisted biopsy studies.

\begin{tabular}{|c|c|c|c|c|c|c|c|}
\hline Study & Material & Number of lesions & Technical success & Duration (min.) & Cancer & High risk & Benign \\
\hline Carbognin et al.(17), 2011 & Vacora 10-gauge & 29 & $27 / 29$ (93\%) & $9-25$ & $11(40 \%)$ & $1(4 \%)$ & $15(56 \%)$ \\
\hline Perlet et al. ${ }^{(\mathbf{1 2})}, 2002$ & Mammotome 11-gauge & 342 & $334 / 342$ (98\%) & Not reported & $84(25 \%)$ & $17(5 \%)$ & $233(70 \%)$ \\
\hline Perlet et al. ${ }^{(13)}, 2006$ & Mammotome 11-gauge & 538 & $517 / 538$ (96\%) & Not reported & $138(27 \%)$ & $17(3 \%)$ & $362(70 \%)$ \\
\hline Liberman et al. ${ }^{(4)}, 2003$ & ATEC 9-gauge & 28 & $27 / 28$ (96\%) & 35 & $6(22 \%)$ & $1(4 \%)$ & $20(74 \%)$ \\
\hline Liberman et al. ${ }^{\text {(18) }}, 2005$ & ATEC 9-gauge & 98 & $95 / 98$ (97\%) & 33 & $24(25 \%)$ & $10(11 \%)$ & $61(64 \%)$ \\
\hline Lehman et al. ${ }^{(\mathbf{1 9 )}}, 2005$ & ATEC 9-gauge & 38 & $38 / 38(100 \%)$ & 38 & $14(37 \%)$ & $2(38 \%)$ & $22(38 \%)$ \\
\hline Orel et al. ${ }^{(20)}, 2006$ & ATEC 9-gauge & 85 & $85 / 85$ (100\%) & Not reported & 52 (61\%) & $18(21 \%)$ & $15(18 \%)$ \\
\hline Gebauer et al. ${ }^{(21)}, 2006$ & Vacora 10-gauge & 44 & $42 / 44$ (95\%) & Not reported & $11(27 \%)$ & $3(7 \%)$ & $28(68 \%)$ \\
\hline Perreta et al. ${ }^{(\mathbf{1 1})}, 2008$ & Vacora 10-gauge & 47 & $47 / 47(100 \%)$ & Not reported & $15(32 \%)$ & $4(8 \%)$ & $28(60 \%)$ \\
\hline Mahoney $^{(\mathbf{2 2})}, 2008$ & EnCor 10-gauge & 55 & $55 / 55(100 \%)$ & Not reported & $10(18 \%)$ & $7(13 \%)$ & $38(55 \%)$ \\
\hline Malhaire et al. ${ }^{(\mathbf{2 3})}, 2010$ & Vacora 10-gauge & 74 & $72 / 74(98 \%)$ & 72 & $33(46 \%)$ & $10(14 \%)$ & $29(40 \%)$ \\
\hline Rauch et al. $.^{(24)}, 2012$ & ATEC 9-gauge & 218 & $218 / 218(100 \%)$ & Not reported & $48(22 \%)$ & $37(17 \%)$ & $133(61 \%)$ \\
\hline Spick et al. ${ }^{(25)}, 2016$ & Vacora, ATEC, and Mammotome & 487 & $487 / 487$ (100\%) & Not reported & $82(17 \%)$ & $77(16 \%)$ & $328(67 \%)$ \\
\hline Ferré et al. ${ }^{(26)}, 2016$ & SenoRx 10-gauge & 259 & $253 / 259$ (98\%) & Not reported & 93 (37\%) & $47(18 \%)$ & $113(45 \%)$ \\
\hline This study & ATEC 9-gauge & 215 & $205 / 215$ (95\%) & 26 & $43(21 \%)$ & $33(16 \%)$ & $129(63 \%)$ \\
\hline
\end{tabular}


as ours (ATEC, 9 gauge), and are in accordance with the international consensus on the topic ${ }^{(16)}$. The duration of the procedure in the present study is comparable to that of stereotactically- and ultrasound-guided vacuum-assisted biopsies, depending mostly on the number of lesions investigated and on the technical difficulties of the procedure, regardless of the localization method used ${ }^{(20-26)}$. We can conclude that vacuum-assisted biopsy is a safe and effective technique for the management of lesions detectable only on MRI.

Of the lesions biopsied in the present study, $63 \%$ were benign, compared with rates ranging from $38 \%$ to $74 \%$ in 13 of the 14 studies selected, the remaining study reporting a rate of $18 \%{ }^{(20)}$. That same study reported the highest rate of malignancy $(61 \%)$, most probably because it evaluated a small sample of selected cases $(n=85)$.

High-risk lesions accounted for $16 \%$ of the lesions in our sample, within the range of $3-21 \%$ reported in 13 of the 14 studies selected for comparison, although the remaining study reported a rate of $38 \%{ }^{(19)}$. We found that such lesions were more common among the non-nodular enhancements.

The overall rate of malignancy found in our study was $21 \%$, and the rate was higher $(22.2 \%)$ among the nonnodular enhancements. Our data are quite similar to those reported by Liberman et al. ${ }^{(18)}$, Rauch et al. ${ }^{(24)}$, Mahoney et al. ${ }^{(22)}$ and Spick et al. ${ }^{(25)}$, although their samples differed from ours. Among our malignant cases, 17 patients (8\% of the sample as a whole) had ductal carcinoma in situ, comparable to the $3-28 \%$ reported in the literature ${ }^{(24,29,30)}$. A finding of ductal carcinoma in situ was also more common among non-nodular enhancements than among nodules, occurring in 14 cases and three cases, respectively.

With regards to the BI-RADS classification, we observed that of the eight lesions classified as probably benign (BI-RADS 3), only one presented a high-risk histopathological result (focal atypical lobular hyperplasia), whereas the other seven were benign. Of the 190 BI-RADS 4 lesions, 39 (20\%) were malignant, 32 (17\%) were high-risk lesions, and $119(63 \%)$ were benign. Of the seven BI-RADS 5 lesions, four were malignant, as expected, and three were benign - one nodule diagnosed as fibroadenoma and two lesions (one nodule and one non-nodular enhancement) diagnosed as usual ductal hyperplasia accompanied by columnar cell changes without atypia.

The BI-RADS system, with its new concepts and terminology, provides the MRI nomenclature with greater clarity and uniformity. It is known that breast MRI scans can usually provide enough information to support a recommendation for a course of action ${ }^{(14)}$. The malignancy rate of lesions classified as BI-RADS 3 is lower than $3 \%$. Such lesions may be investigated in specific situations, especially in high-risk patients with a history of breast or ovarian cancer. Histological investigation is indicated for all lesions classified as BI-RADS 4 on MRI, because this category has a highly variable likelihood of malignancy (3-94\%) and is not divided into the subcategories 4A, 4B and 4C (low, intermediate and high level of suspicion, respectively) for MRI, as it is for other imaging methods. BIRADS 5 lesions present a more than $95 \%$ probability of malignancy and must also be investigated ${ }^{(14)}$.

Our results, notably our finding of a 57\% malignancy rate among BI-RADS 5 lesions, lead us to question the BIRADS classification used in the procedures included in our sample, because the physician who performed the procedures did not re-evaluate the BI-RADS classification. This reveals the fact that there is a necessary learning curve for professionals using the BI-RADS classification in MRI studies, highlighting the importance of having dedicated breast radiologists to perform the test. In addition, one should consider the possibility of false-negatives in MRIguided biopsies, especially in biopsies of non-nodular lesions, because we did not have follow-up or surgical data for the patients involved.

Of the 205 patients in our sample, 76 had malignant or high-risk lesions and were appropriately referred for surgery, thus receiving proper care. Likewise, the remaining patients (those with benign results, a bit over half of the sample) were spared an unnecessary, costly surgery that would certainly have had physical and psychological consequences for their lives, which shows how impactful this procedure can be.

\section{CONCLUSION}

MRI-guided vacuum-assisted biopsy is a method that is well tolerated, simple, safe, useful, and reproducible. However, the identification and correct classification of a lesion detectable only on MRI are critical for appropriately referring patients for biopsy. At our center, we found a $21 \%$ malignancy rate, which is in agreement with the findings of other studies in the literature. Because this was a preliminary study, studies involving the correlation with surgical data and evaluating patients over longer follow-up periods are needed in order to evaluate the true accuracy of the methods employed. To our knowledge, there are no similar data in the literature of Brazil. Therefore, our study is one of the first in this field.

\section{REFERENCES}

1. Shetty MK. The basic of breast MRI. In: Shetty MK, editor. Breast cancer screening and diagnosis: a synopsis. 1st ed. New York, NY: Springer Science; 2015. p. 165-7.

2. Sardanelli F, Boetes C, Borisch B, et al. Magnetic resonance imaging of the breast: recommendations from the EUSOMA working group. Eur J Cancer. 2010;46:1296-316.

3. Schnall M, Orel S. Breast MR imaging in the diagnostic setting. Magn Reson Imaging Clin N Am. 2006;14:329-37, vi.

4. Liberman L, Morris EA, Dershaw DD, et al. Fast MRI-guided vacuum-assisted breast biopsy: initial experience. AJR Am J Roentgenol. 2003;181:1283-93.

5. Eby PR, Lehman CD. Magnetic resonance imaging-guided breast interventions. Top Magn Reson Imaging. 2008;19:151-62.

6. Peters NHGM, Rinkes IHMB, Zuithoff NPA, et al. Meta-analysis 
of MR imaging in the diagnosis of breast lesions. Radiology. 2008; 246:116-24.

7. Orel SG, Schnall MD, Newman RW, et al. MR imaging-guided localization and biopsy of breast lesion: initial experience. Radiology. 1994;193:97-102.

8. Kuhl CK, Elevelt A, Leutner CC, et al. Interventional breast MR imaging: clinical use of a stereotactic localization and biopsy device. Radiology. 1997;204:667-75.

9. Arantes Pereira FP, Martins G, Calas MJG, et al. Magnetic resonance imaging-radioguided occult lesion localization (ROLL) in breast cancer using Tc-99m macro-aggregated albumin and distilled water control. BMC Med Imaging. 2013;13:33.

10. Arantes Pereira FP. Biópsia a vácuo de mama orientada por ressonância magnética. In: Franco JM, organizador. Cirurgia da mama - diagnóstico, tratamento, reconstrução, estética. $1^{\text {a }}$ ed. Rio de Janeiro, RJ: Revinter; 2012. p. 3-11.

11. Perretta T, Pistolese CA, Bolacchi F, et al. MR imaging-guided 10 -gauge vacuum-assisted breast biopsy: histological characterisation. Radiol Med. 2008;113:830-40.

12. Perlet C, Heinig A, Prat X, et al. Multicenter study for the evaluation of a dedicated biopsy device for MR-guided vacuum biopsy of the breast. Eur Radiol. 2002;12:1463-70.

13. Perlet C, Heywang-Kobrunner SH, Heinig A, et al. Magnetic resonance-guided, vacuum-assisted breast biopsy: results from a European multicenter study of 538 lesions. Cancer. 2006;106:982-90.

14. American College of Radiology. ACR BI-RADS - magnetic resonance imaging. In: ACR BI-RADS atlas: breast imaging reporting and data system. 2nd ed. Reston, VA: American College of Radiology; 2013.

15. Eby PR, Lehman C. MRI-guided breast interventions. Semin Ultrasound CT MR. 2006;27:339-50.

16. Heywang-Köbrunner SH, Sinnatamby R, Lebeau A, et al. Interdisciplinary consensus on the uses and technique of MR-guided vacuum-assisted breast biopsy (VAB): results of a European consensus meeting. Eur J Radiol. 2009;72:289-94.

17. Carbognin G, Girardi V, Brandalise A, et al. MR-guided vacuum-assisted breast biopsy in the management of incidental enhancing lesions detected by breast MR imaging. Radiol Med. 201 1;116:876-85.
18. Liberman L, Bracero N, Morris E, et al. MRI-guided 9-gauge vacuum-assisted breast biopsy: initial clinical experience. AJR Am J Roentgenol. 2005;185:183-93.

19. Lehman CD, Deperi ER, Peacock S, et al. Clinical experience with MRI-guided vacuum-assisted breast biopsy. AJR Am J Roentgenol. $2005 ; 184: 1782-7$.

20. Orel SG, Rosen M, Mies C, et al. MR imaging-guided 9-gauge vacuum-assisted core-needle breast biopsy: initial experience. Radiology. 2006;238:54-61.

21. Gebauer B, Bostanjoglo M, Moesta KT, et al. Magnetic resonanceguided biopsy of suspicious breast lesions with a handheld vacuum biopsy device. Acta Radiol. 2006;47:907-13.

22. Mahoney MC. Initial clinical experience with a new MRI vacuumassisted breast biopsy device. J Magn Reson Imaging. 2008;28:9005.

23. Malhaire C, El Khoury C, Thibault F, et al. Vacuum-assisted biopsies under MR guidance: results of 72 procedures. Eur Radiol. 2010;20:1554-62.

24. Rauch GM, Dogan BE, Smith TB, et al. Outcome analysis of 9-gauge MRI-guided vacuum-assisted core needle breast biopsies. AJR Am J Roentgenol. 2012;198:292-9.

25. Spick C, Schernthaner M, Pinker K, et al. MR-guided vacuum-assisted breast biopsy of MRI-only lesions: a single center experience. Eur Radiol. 2016;26:3908-16.

26. Ferré R, Ianculescu V, Ciolovan L, et al. Diagnostic performance of MR-guided vacuum-assisted breast biopsy: 8 years of experience. Breast J. 2016;22:83-9.

27. Brennan SB, Sung JS, Dershaw DD, et al. Cancellation of MR imaging-guided breast biopsy due to lesion nonvisualization: frequency and follow-up. Radiology. 2011;261:92-9.

28. Meeuwis C, Veltman J, Hall HNV, et al. MR-guided breast biopsy at 3T: diagnostic yield of large core needle biopsy compared with vacuum-assisted biopsy. Eur Radiol. 2012;22:341-9.

29. Verheyden C, Pages-Bouic E, Balleyguier C, et al. Underestimation rate at MR imaging-guided vacuum assisted breast biopsy: a multiinstitutional retrospective study of 1509 breast biopsies. Radiology. 2016;281:708-19. 